\author{
Christos Arvanitidis · Georgios Chatzigeorgiou \\ Drosos Koutsoubas · Theodoros Kevrekidis \\ Costas Dounas · Anastasios Eleftheriou \\ Panayota Koulouri · Athanasios Mogias
}

\title{
Estimating lagoonal biodiversity in Greece: comparison of rapid assessment techniques
}

Received: 2 May 2004 / Revised: 31 January 2005/ Accepted: 2 February 2005 / Published online: 15 March 2005 (C) Springer-Verlag and AWI 2005

\begin{abstract}
An attempt is made to compare the results of different rapid biodiversity assessment techniques at the pan-Mediterranean, sectorial and local levels. A uniform multivariate pattern exists at the pan-Mediterranean and national (sectorial) levels: lagoons can be different when they host only a few species, but as species numbers increase, lagoons become homogenous in composition. Multivariate techniques cannot distinguish anthropogenically-impacted lagoons from those, which are naturally disturbed. In the pan-Mediterranean context it is the higher taxonomic levels, but in the national and local context it is the most abundant macrobenthic groups (polychaetes, molluscs and crustaceans) and meiobenthos which provide patterns closest to that derived from the species level. Taxonomic distinctness indices applied to polychaete and mollusc inventories provide meaningful results at most levels and scales of observation. These indices seem to be robust enough to discriminate anthropogenically impacted from naturally disturbed lagoons.
\end{abstract}

Communicated by H.-D. Franke

C. Arvanitidis $(\bowtie) \cdot$ G. Chatzigeorgiou $\cdot$ C. Dounas

A. Eleftheriou · P. Koulouri

Hellenic Centre for Marine Research,

Institute of Marine Biology and Genetics,

Heraklion, Crete,

71003, Greece

E-mail: arvanitidis@imbc.gr

Tel.: + 30-2810-337748

Fax: + 30-2810-337822

D. Koutsoubas

Department of Marine Science,

University of the Aegean,

Mytilene, Lesbos,

81100, Greece

T. Kevrekidis · A. Mogias

Laboratory of Environmental Research and Education,

Democritus University of Thrace,

68100, Alexandroupolis, Greece
Keywords Biodiversity $\cdot$ Macrofauna

Mediterranean $\cdot$ Multivariate analysis

Taxonomic distinctness

\section{Introduction}

Coastal lagoons are shallow soft-bottom systems which experience frequent and unpredictable fluctuations in their environmental variables, which often result in severe alterations of the structure and distribution pattern of organisms. It has been strongly argued that lagoonal systems are different from estuaries, their brackish counterparts of the paralic domain (Kjerfve 1994).

The concept of the paralic domain and its zonation along the marine-freshwater axis was introduced by Guelorget and Perthuisot (1983). It has been proposed that six zones can be defined along this axis, each hosting a particular combination of species which originate from three domains: marine, lagoonal or freshwater. According to this theory, confinement (referring to the time of renewal of the components of marine origin) is the factor controlling the organization of the communities (Guelorget and Perthuisot 1992). However, Barnes (1994) has argued that although the confinement concept may be applicable to large and microtidal lagoons, such as many of those occurring in the Mediterranean, it cannot nevertheless be used to describe the community organization of the corresponding environments of the macrotidal European regions.

Over the last three decades, the scope of macrofaunal research in the Mediterranean lagoonal environment has been extended to include descriptive studies (e.g. Nikolaidou et al. 1988; Gravina et al. 1989; Lardicci et al. 1997) and methods to assess levels of disturbance (Reizopoulou et al. 1996). Initial valuation of the Mediterranean coastal lagoons for conservation and management purposes has been based primarily on food resources (local fishing and aquaculture) and on their 
use by visiting, over-wintering and migrating birds (Barnes 1991). Not surprisingly, biodiversity has never been used for this purpose.

The recent development of rapid biodiversity assessment techniques, in response to various European and international treaties and conventions, has provided the scientific community with additional tools which can assist the monitoring and valuation of lagoonal environments. The most commonly used methodological approaches include: (1) the taxonomic sufficiency perspective, i.e. multivariate techniques applied to higherthan-species taxonomic levels (e.g. Warwick 1988; Ferraro and Cole 1990, 1992, 1995; Warwick et al. 1990; Somerfield and Clarke 1995; Olsgard et al. 1997); (2) the taxonomic distinctness perspective, i.e. sample-size/sample-effort free biodiversity indices, which take into account not only the species richness information but also the classification of species to higher categories along the phylogenetic/taxonomic tree (Warwick and Clarke 1995, 1998, 2001; Clarke and Warwick 2001).

However, these techniques have only recently been applied to the Mediterranean lagoonal ecosystem. In a recent study, Arvanitidis et al. (2005) suggested that although the application of these rapid biodiversity assessment techniques has proved to be useful and efficient at the pan-Mediterranean level, they should nevertheless also be applied at lower levels and scales of observation.

The objective of this study is to test whether these rapid biodiversity assessment techniques, as a prerequisite for their wider application, have a stable response when applied at the pan-Mediterranean, sectorial and local levels of observation.

\section{Methods}

\section{Data resources}

Seven Greek lagoons, sampled on at least a seasonal basis, have been considered in this study. The locations of these lagoons and the total number of species of the most abundant macrofaunal groups (polychaetes, molluscs, crustaceans) they host, are given in Fig. 1. At the local scale, macrofaunal data from the Gialova lagoon were examined. Positions of the sampling stations and of the surrounding environments of the lagoon are given in Fig. 2. Information on species' distribution in the Greek lagoons are based on published studies by Reizopoulou et al. (1996; Tsopeli and Vivari), Nikolaidou et al. (1998; Messolonghi), Koutsoubas et al. (2000; Gialova) and unpublished data (T. Kevrekidis, A. Mogias, personal communication; Laki, Drana, Monolimni).

Sustainable fisheries and aquaculture activities are carried out in most of the afore-mentioned lagoons. Comprehensive analytical methodology applied to the above Greek lagoons, including species richness, diversity indices, multivariate analyses and graphical methods (distribution of geometric abundance and geometric size classes, ABC curves, etc.), have shown that all but one of the above lagoons can be considered as naturally stressed ecosystems, typical of Mediterranean lagoonal environments (e.g. Reizopoulou et al. 1996; Nikolaidou et al. 1998; Koutsoubas et al. 2000). However, Drana lagoon is considered as severely impacted by anthropogenic activities associated with the occlusion of the former marine canal opening, which usually results in the
Fig. 1 Map of Greece, indicating locations of the lagoonal systems considered in the present study. Numbers on the top of columns indicate number of species belonging to the most abundant macrobenthic groups (polychaetes, molluses and crustaceans; with the exception of Messolonghi lagoon, where no valid information exists for crustaceans)

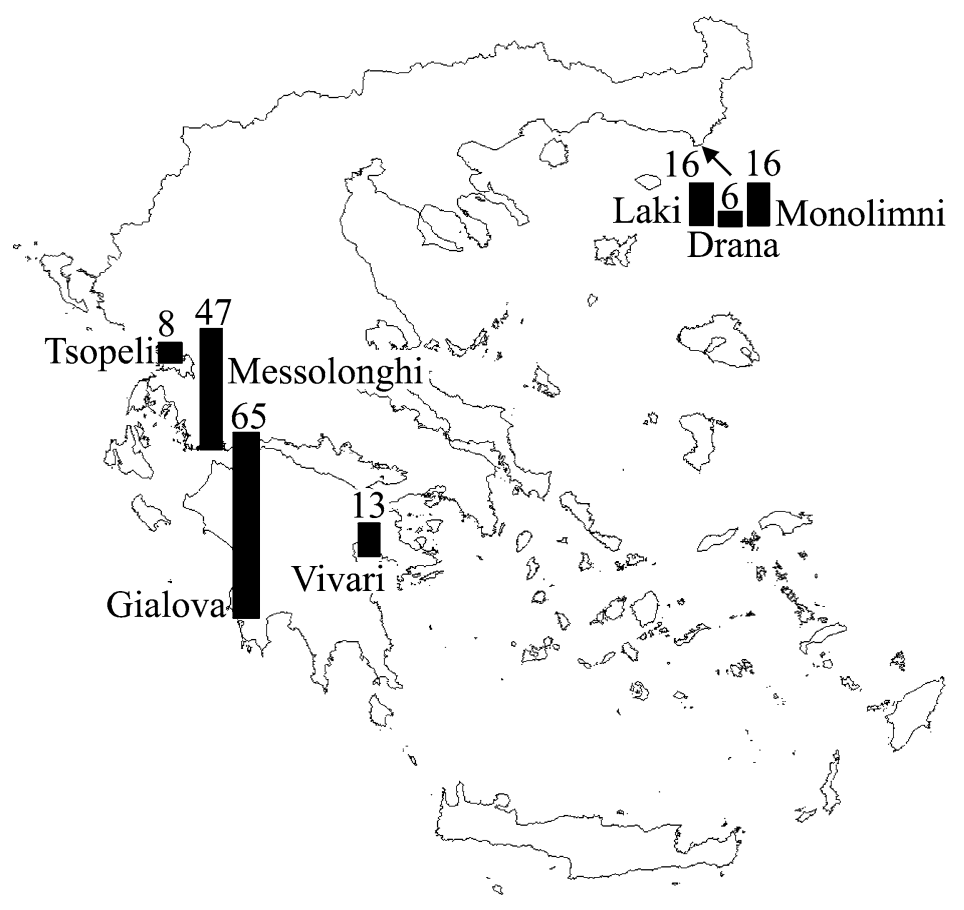


Fig. 2 Map of Gialova lagoon, indicating the sampling stations and the surrounding environments

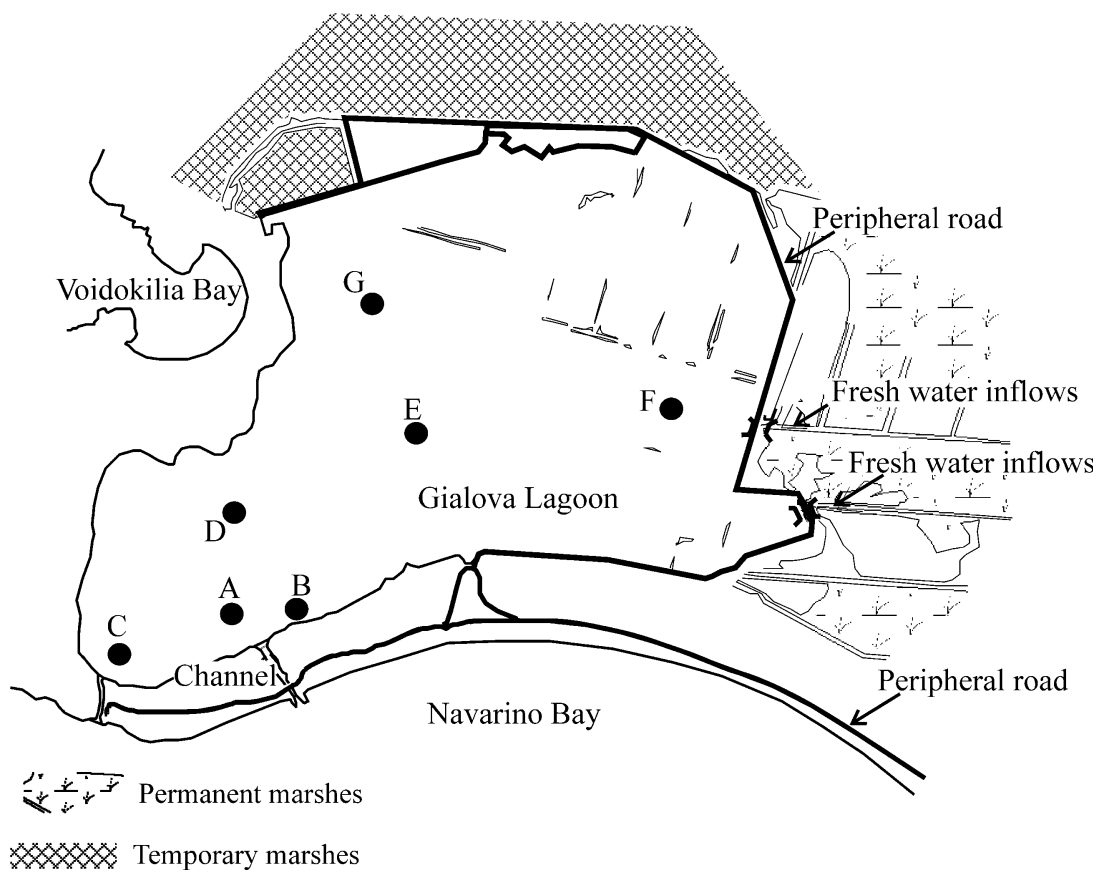

temporal reclamation of the lagoon (T. Kevrekidis, A. Mogias, personal communication).

Three initial binary (presence/absence) matrices were constructed, covering the distribution of all macrofaunal species belonging to the most abundant groups (polychaetes, molluscs, crustaceans) in the Greek lagoons, and their distribution in the Gialova lagoon on both spatial (stations) and temporal (seasons) scales. The information included in these initial matrices was subsequently aggregated into five taxonomic levels (from genus to phylum). Three additional subsets of the initial matrices, including information on the distribution of each of the most abundant groups, were constructed and used in subsequent analyses. An additional matrix containing information on the spatio-temporal distribution of the meiobenthic fauna in the Gialova lagoon (McArthur et al. 2000) was also taken into account.

\section{Mathematical analyses}

Multivariate patterns of taxa distribution in the Greek lagoons (national level) and in the Gialova lagoon (local level) were derived by using the non-metric multidimensional scaling technique (nMDS), as proposed by Clarke and Warwick (1994). Similarity matrices were obtained from the binary ones by using Sørensen's similarity coefficient (Legendre and Legendre 1998). Goodness-of-fit of the resulting two-dimensional plots was measured by applying Kruskal's stress formula I (Clarke and Green 1988). Multivariate patterns deriving from different taxonomic levels and from the most abundant groups were compared by means of the second-stage MDS technique (Somerfield and Clarke 1995).
Macrofaunal biodiversity was assessed by means of the recently developed sample-size, sample-effort free indices of average and variation in taxonomic distinctness (Warwick and Clarke 1998; Clarke and Warwick 2001). The indices were calculated from the inventories of the benthic macrofauna (most abundant groups) and from the species list of polychaetes, molluscs and crustaceans, both at national and local levels of observation. Simulation funnels were constructed from random subsets of species from the national species pool of the lagoonal ecosystem, at all levels and scales of observation. Monotonic relationships between the calculated taxonomic distinctness indices were explored using Spearman's rank correlation coefficient.

\section{Results}

National scale

\section{Overall pattern}

The grouping of Greek lagoons, based on their similarity in faunal composition, is given in Fig. 3a. Three different lagoonal groups can be recognized, showing a "fanshaped" arrangement on the MDS plot: The first group includes lagoons from both the Ionian and Aegean Seas, namely Tsopeli and Vivari lagoons, which are characterized by low numbers of species ( $8-13$ species). In the second group, the coastal lagoons Messolonghi and Gialova are included, with the highest number of species (45-67); taking into account that there are no valid data on the crustacean fauna of the Messolonghi lagoon, the total number of macrofaunal species being present in 


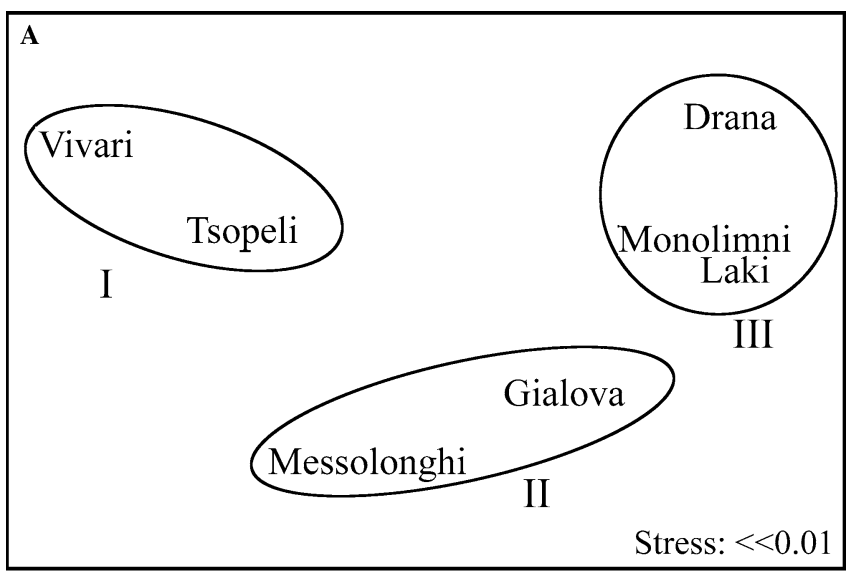

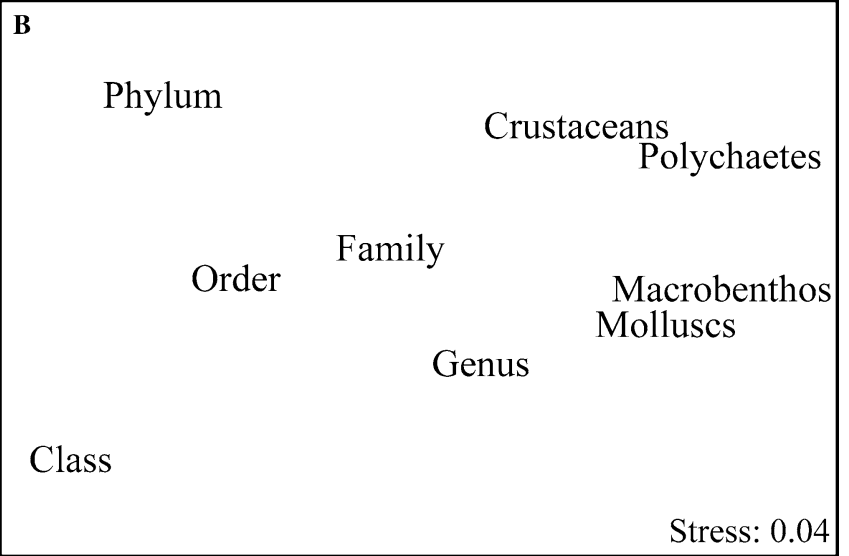

Fig. 3 Mutlivariate pattern on the national level of observation. a Non-metric multidimensional scaling plot, showing the groups of Greek lagoonal systems; b second-stage ordination by MDS of ranked intermatrix correlations; matrices include information on species and higher taxonomic categories as well as information on species of the most abundant groups (polychaetes, molluscs and crustaceans)

this lagoon may be very close to the numbers found in Gialova lagoon. The last group is formed exclusively by lagoons located in the vicinity of the Evros river (northern Aegean Sea), with low numbers of species (616).

\section{Aggregated information}

Comparison of the patterns derived from the most abundant groups and from higher taxonomic levels (from genus to phylum) with the one derived from the total macrofaunal species is shown in the second-stage MDS plot (Fig. 3b). It is clearly depicted that similarity patterns derived from the most abundant groups are closer to the multivariate pattern pertinent to the total lagoonal macrofauna, rather than to those derived from the higher taxonomic levels. However, there is one exception to this general pattern: the pattern derived from the generic level is closer to the one based on the species level (for the total macrofauna), than to the one resulting from the crustaceans. Patterns based on molluses, polychaetes and genera are ranked as first, second and third most closely related to the pattern based on the total benthic species occurring in the Greek lagoons.

\section{Taxonomic distinctness}

The simulated distribution funnels of the average taxonomic distinctness $\left(\Delta^{+}\right)$and of the variation in taxonomic distinctness $\left(\Lambda^{+}\right)$, with the calculated corresponding values for the Greek lagoons, superimposed on the plots, are given in Fig. 4. Similar graphs have been also produced for the most abundant groups.

Only Messolonghi lagoon has a lower than expected $\Delta^{+}$value in the funnel produced by the total macrobenthic fauna, a fact which is attributed to the absence of data on crustacean species (Fig. 4ai). Also, the $\Delta^{+}$ values of three Greek lagoons, Gialova, Vivari and Drana, are borderline. None of the $\Delta^{+}$values, calculated from the polychaete, mollusc and crustacean inventories of the Greek lagoons, is located outside the expected distribution. Although none of the lagoons has a $\Lambda^{+}$value falling outside the expected distribution when $\Lambda^{+}$is calculated for the total macrobenthic fauna, Drana lagoon always has a lower than expected $\Lambda^{+}$ value when $\Lambda^{+}$is calculated separately for the polychaete, mollusc and crustacean species (Fig. 4b). Gialova lagoon also produces a lower than expected $\Lambda^{+}$ value for crustaceans.

\section{Local scale}

\section{Spatial and temporal patterns}

The overall spatial pattern derived from the macrofaunal (species) and meiofaunal (major categories) levels is given in Fig. 5a, b. The gradient from the faunistically richer stations located near the marine canal opening $(\mathrm{A}, \mathrm{B})$ to the most isolated and impoverished stations (E, F, G), is clearly reflected in the MDS plot (Fig. 5a). Stations located between these two extremities $(\mathrm{C}, \mathrm{D})$ also show an intermediate position in the plot.

A substantially different pattern is derived from the meiobenthic data. Here (Fig. 5b), four groups of stations can be distinguished: the first and second groups include both stations located near the canal opening and in an intermediate location, while groups 3 and 4 are represented by the most isolated stations $F$ and $G$, respectively. However, meiobenthos produces a pattern almost identical to that derived from the macrobenthos when calculations are based on density values (McArthur et al. 2000).

Macrobenthos and meiobenthos are characterized by convergent ordination plots on the seasonal scale. In both plots (Fig. 5c, d) summer and spring are closely related while winter and autumn are placed on opposite sites of the plots. 
Fig. 4 The $95 \%$ probability funnels for the average taxonomic distinctness (a) and for the variation in taxonomic distinctness (b). Expected averages are indicated by the straight line in the middle of the funnel. Funnels have been constructed based both on the entire macrofaunal inventory $(i)$ and on the polychaete, mollusc and crustacean inventories $(i i-i v)$ of the Greek lagoons
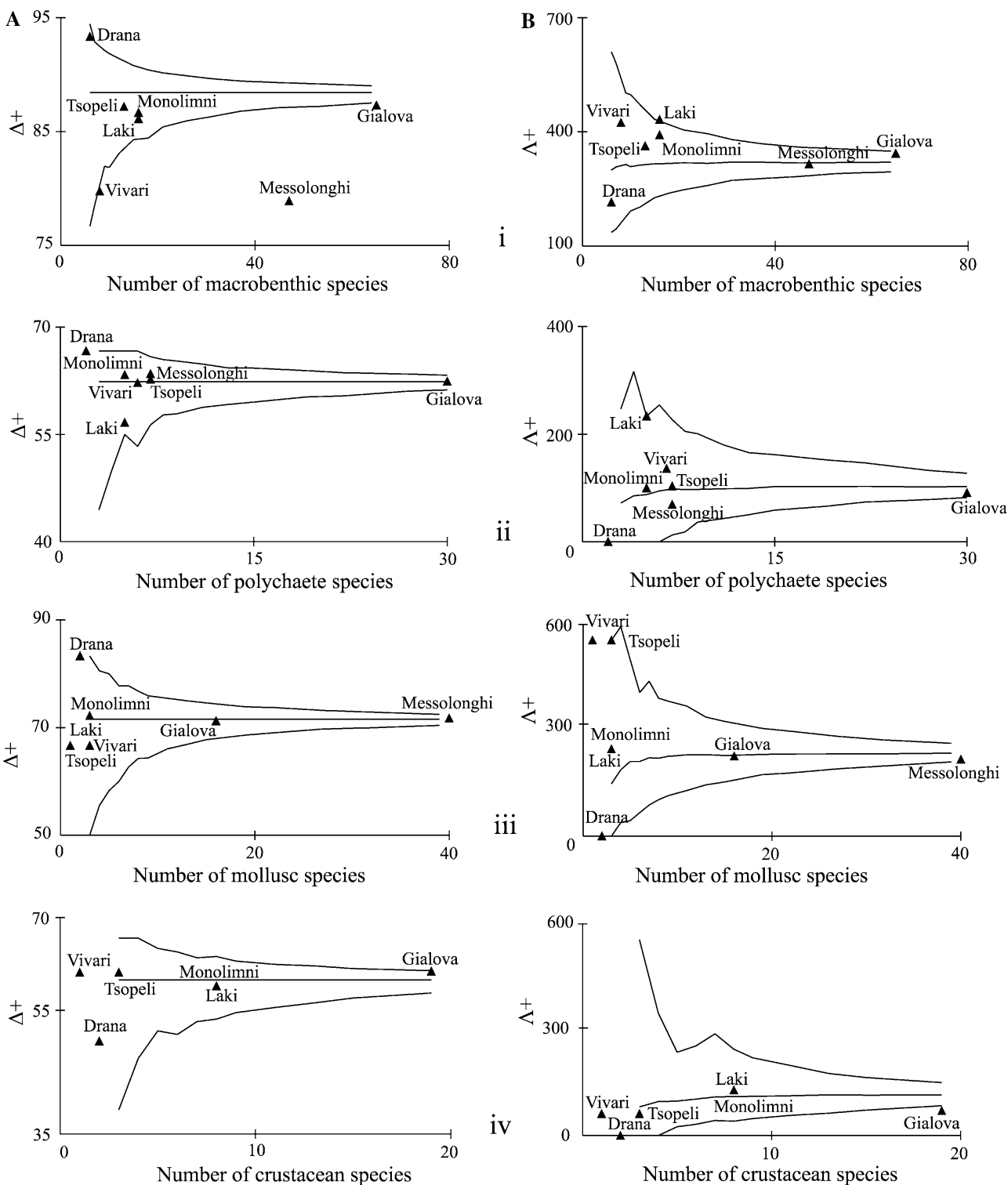

\section{Aggregated information}

A comparison of patterns derived from the meiobenthos, the total macrobenthos, and the most abundant macrobenthic groups is given in the second-stage MDS plots (Fig. 6). On the spatial scale (Fig. 6a), patterns derived from polychaete, mollusc and crustacean species and from meiobenthos are respectively ranked as first, second, third and fourth, closely related to the pattern stemming from the total macrobenthic species. Temporal patterns derived from the meiobenthos and polychaete species appear to be more closely related to the one derived from the total macrobenthic species than to those stemming from the crustacean and the mollusc species lists (Fig. 6b).

\section{Taxonomic distinctness}

The distribution funnels of the average taxonomic distinctness $\left(\Delta^{+}\right)$and variation in taxonomic distinctness
$\left(\Lambda^{+}\right)$as calculated from the simulation procedure, along with the corresponding values calculated from the macrobenthic species present in each station and season, are given in Figs. 7 and 8, respectively. Graphs deriving from the same simulation procedure have also been produced for the most abundant groups.

There are no stations falling outside the expected distribution where $\Delta^{+}$is calculated from the total macrobenthos and polychaete species, while some stations show $\Delta^{+}$values located borderline or outside the funnel if $\Delta^{+}$is calculated from the mollusc and crustacean species lists (Fig. 7a). Conversely, $\Lambda^{+}$values located borderline or outside the funnels appear only in the cases of total macrobenthos and polychaetes (Fig. 7b).

On the seasonal level, only spring falls outside the expected ranges of $\Delta^{+}$and $\Lambda^{+}$values (Fig. 8 ai, bi) if these are calculated from the total macrobenthic species list. In the remaining simulation funnels, derived from the polychaete, mollusc and crustacean species lists 
Fig. 5 Multivariate pattern at the local level of observation. a, b MDS plots, showing groups of stations in the Gialova lagoon (spatial scale) as derived from the macrobenthic and meiobenthic data; c, d MDS plots, showing groups of seasons in the Gialova lagoon (temporal scale) as derived from the macrobenthic and meiobenthic data
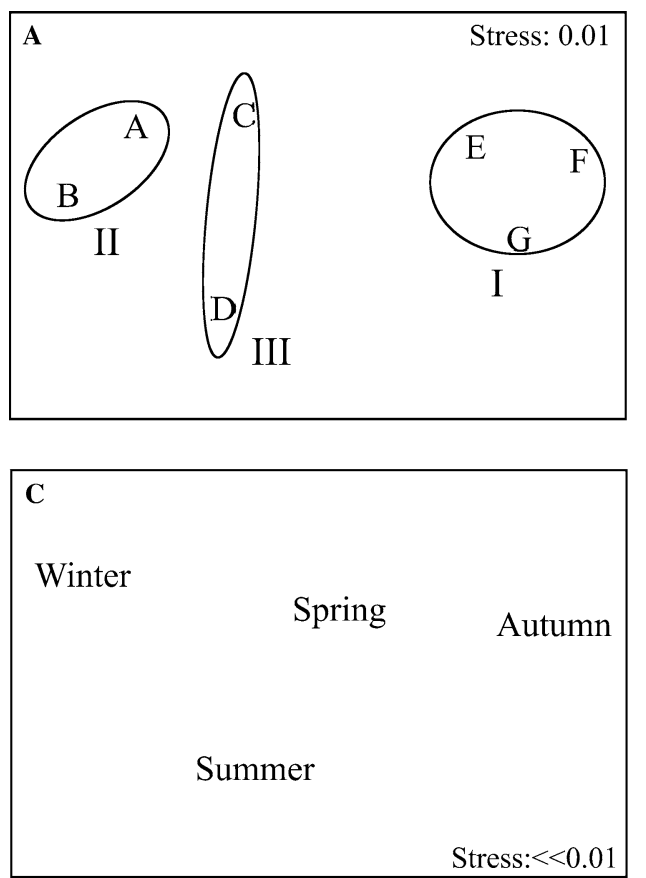

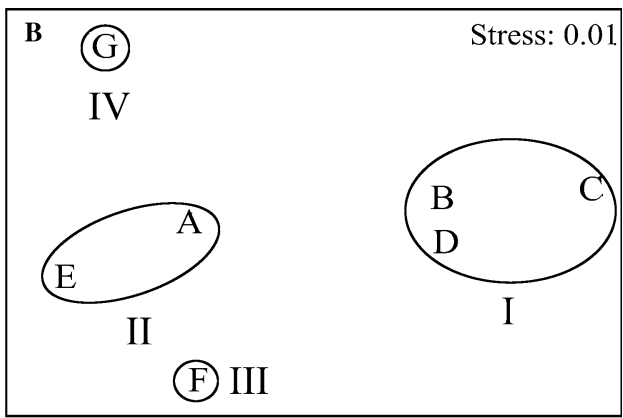

D

Spring

Summer

Winter

Autumn

\section{$\mathbf{A}$}

Molluscs

Macrobenthos

Polychaetes

Crustaceans

Stress: $<<0.01$

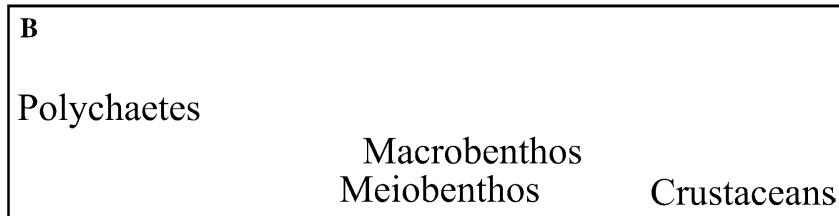

Molluscs

Stress: $<<0.01$

Fig. 6 Multivariate pattern at the local level of observation (Gialova lagoon). a Second-stage MDS plots of ranked intermatrix correlations on the spatial scale; matrices include information on species from the most abundant groups (polychaetes, molluscs and crustaceans), as well as information on macro- and meiobenthos (higher categories); b as above, but on the temporal (seasonal) scale from the Gialova lagoon, all seasons are found to be within the expected range.

Spearman's rank correlation coefficient for sets of calculated $\Delta^{+}$and $\Lambda^{+}$values gave negative significant results only when the calculation was based on the polychaete inventory at the national $(\rho=-0.96$; $P<0.005)$ and local level as well as on the spatial scale $(\rho=-0.89 ; P<0.01)$. These results show that the taxonomic distinctness indices are monotonically related in the above cases, and thus should not be used simultaneously for biodiversity assessment purposes.

\section{Discussion}

A comparison of the lagoonal attributes at the panMediterranean, national and local level, as derived from the application of rapid assessment techniques, is provided in Table 1. Results referring to the pan-Mediterranean level are derived from Arvanitidis et al. (2005). Although only the presence/absence of species has been considered, certain meaningful conclusions can be drawn.

Both at the pan-Mediterranean and national levels there exists a uniform multivariate pattern: lagoonal systems are distinct when the number of hosted species is low; when this number is increased, however, homogenization of the costal lagoonal macrobenthic fauna emerges as the common pattern. This pattern has been attributed to the relatively narrow species pool of the Mediterranean lagoonal ecosystem, a fact which raises the probability of species being shared in common by lagoons with high species richness. However, multivariate techniques based on species' distribution matrices 
Fig. 7 The $95 \%$ probability funnels for the average taxonomic distinctness (a) and for the variation in taxonomic distinctness (b). Expected averages are indicated by the straight line in the middle of the funnel. Funnels have been constructed based both on the entire macrofaunal inventory $(i)$ and on the polychaete, mollusc and crustacean inventories (ii-iv) of the Gialova lagoon (spatial scale). Letters $(A-G)$ in the plots indicate sampling stations in the Gialova lagoon (as in Fig. 2)
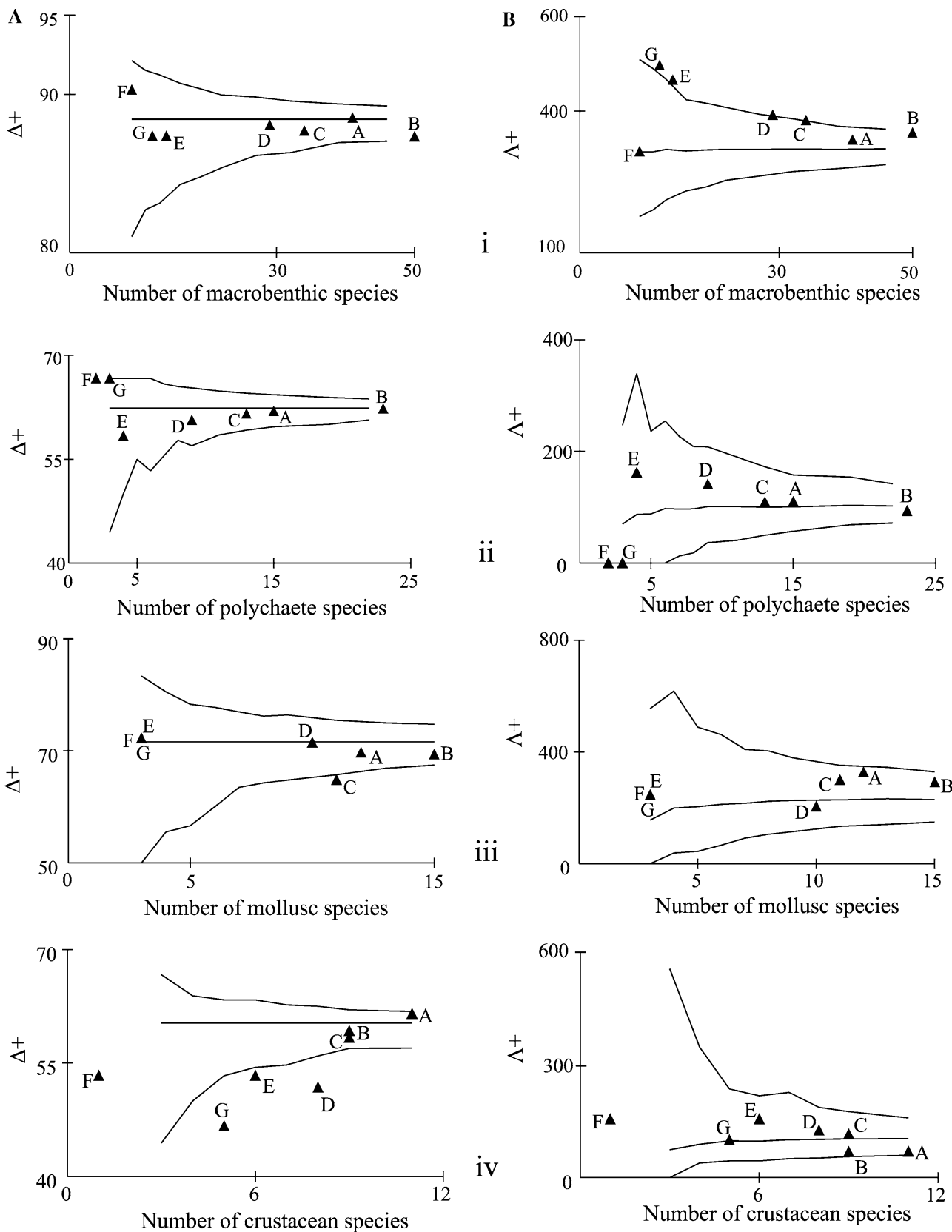

cannot distinguish anthropogenically-impacted lagoons from those naturally stressed, neither at the pan-Mediterranean nor at the national level.

Different patterns, however, occur at the local level. On the spatial scale, the well-known marine-freshwater gradient is observed (e.g. Guelorget and Perthuisot 1992), while on the temporal scale the aforementioned pattern reappears: seasons with low numbers of species tend to be distinct from each other, while those with higher numbers of species show a rather homogenous faunal composition.

Multivariate patterns derived from aggregated information reveal that there is an inverse pattern when one moves from the pan-Mediterranean to the national and local levels of observation: at the pan-Mediterra- nean level, higher taxonomic groups (genus to family) tend to provide patterns close to that derived from the species level, while at the national and local levels the most abundant macrofaunal groups and meiobenthos tend to replace higher taxonomic categories in this respect. Polychaetes and molluscs provide patterns most closely related to the one derived from the species level, while meiobenthos comes first in order only on a temporal scale at the local level. Both of the above macrofaunal groups, as well as the meiobenthos, include the majority of the trophic groups, and are hence most closely related to the functional diversity of the lagoonal environment (Arvanitidis et al. 1999; Koutsoubas et al. 2000; McArthur et al. 2000; Cognetti and Maltagliati 2000). Unfortunately, there are no corresponding results 
Fig. 8 The $95 \%$ probability funnels for the average taxonomic distinctness (a) and for the variation in taxonomic distinctness (b). Expected averages are indicated by the straight line in the middle of the funnel. Funnels have been constructed based both on the entire macrofaunal inventory $(i)$ and on the polychaete, mollusc and crustacean inventories (ii-iv) of the Gialova lagoon (temporal scale)
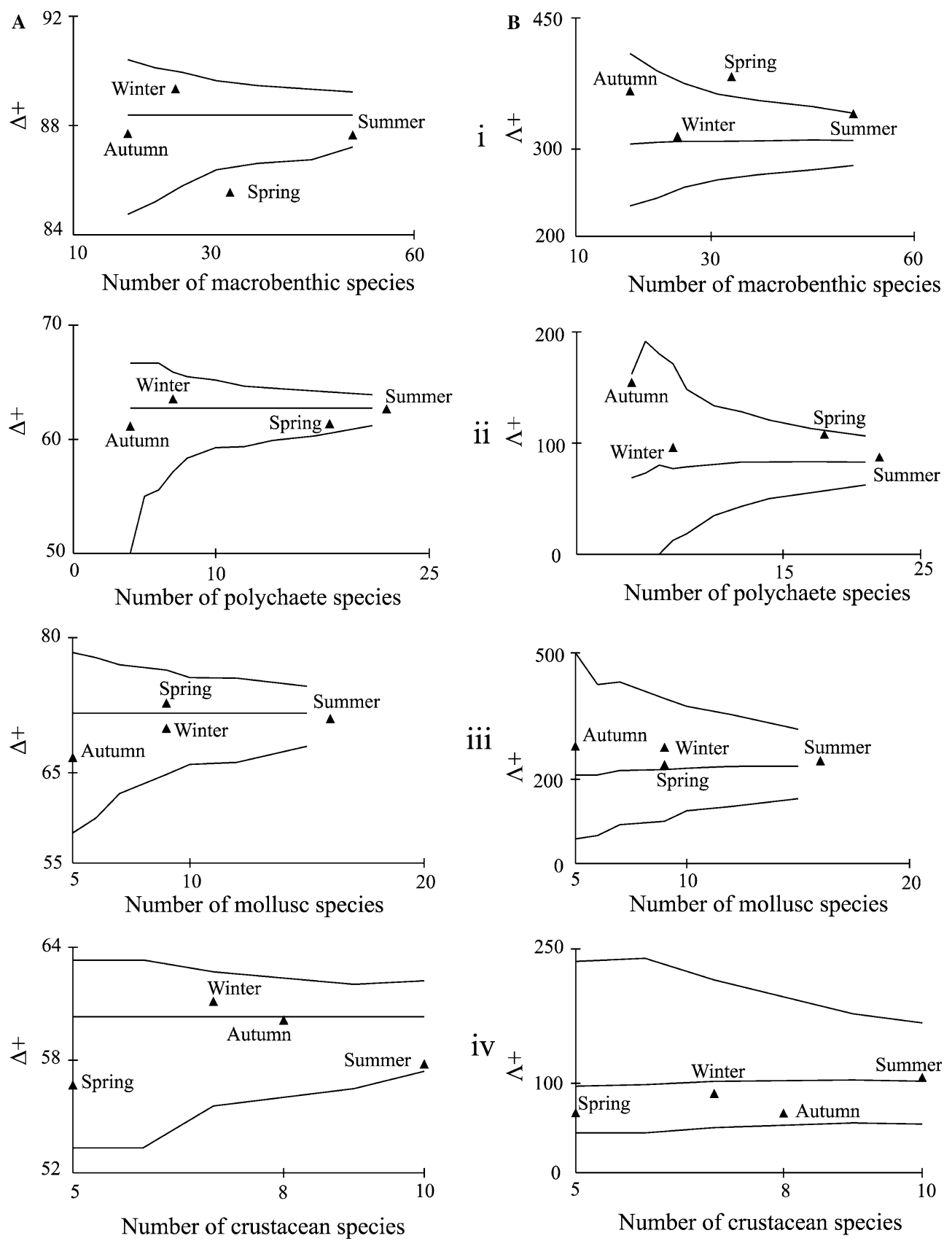

derived from the performance of this technique on the coastal soft-bottom communities and comparing the higher taxonomic levels to the most abundant macrobenthic groups in other parts of the world (e.g. Warwick et al. 1990; Ferraro and Cole 1992, 1995).

Both taxonomic distinctness indices show that polychaetes and molluscs are the macrofaunal groups giving the most meaningful results on most levels and scales of observation, with two exceptions: (1) at the pan-Mediterranean level, only crustaceans may give meaningful results when average taxonomic distinctness is calculated; and (2) on the spatial scale at the local level, the macrobenthos comes first in order, being followed by polychaetes if the average taxonomic distinctness is calculated, and by molluscs if the variation in taxonomic distinctness index is calculated. In the remaining cases, at the national level, only the severely impacted lagoon of Drana falls outside the expected range when $\Lambda^{+}$is calculated from the polychaete, mollusc and crustacean lagoonal inventories. At the local level all seasons are located within the funnels, when the taxonomic distinctness indices are calculated for each of the most abundant groups, indicating very little or no anthropogenic impact on the Gialova lagoon, as concluded by Arvanitidis et al. (1999) and Koutsoubas et al. (2000). The weakness of the performance of these biodiversity indices on the total macrobenthic fauna, and the robustness of their application 
on the most abundant groups, have also been observed at the pan-Mediterranean level by Arvanitidis et al. (2005). This paradox has been attributed to the fact that the degree to which the various taxa are under- or over-represented throughout the taxonomic tree is more pronounced in the cases of the most abundant groups than in the case of the total macrobenthic fauna. This explanation is further supported by the findings of the present study at the national and local levels. A similar situation, in which values of both taxonomic distinctness indices were within the expected range in the case of gastropod molluscs, but fell outside the expected range in the case of the total shelled molluscan fauna (gastropods and bivalves), was observed in the thanatocoenoses of the sandflats of the Isles of Scilly (Warwick and Light 2001).

In conclusion, the application of the previously discussed rapid biodiversity assessment techniques appears to provide meaningful and comparable, if not convergent, results at the pan-Mediterranean, national and local levels. However, their application should be used with caution in the lagoonal systems located in other areas of the Mediterranean, in which they have not been tested at the sectorial and local levels.

Acknowledgements The authors are much indebted to Mrs. Margaret Eleftheriou for the critical reading of the manuscript.

\section{References}

Arvanitidis C, Koutsoubas D, Dounas C, Eleftheriou A (1999) Annelid fauna of a Mediterranean lagoon (Gialova lagoon, sout-west Greece): community structure in a severely fluctuating environment. J Mar Biol Ass UK 79:849-856

Arvanitidis C, Chatzigeorgiou G, Koutsoubas D, Dounas C, Eleftheriou A, Koulouri P (2005) Mediterranean lagoons revisited: weakness and efficiency of the rapid biodiversity assessment techniques in a severely fluctuating environment. Biodivers Conserv (in press)

Barnes RSK (1991) European estuaries and lagoons: a personal overview of problems and possibilities for conservation and management. Aquat Conserv 1:79-87

Barnes RSK (1994) A critical appraisal of the application of Guelorget and Perthuisot's concepts of the paralic ecosystem and confinement to macrotidal Europe. Estuar Coast Shelf Sci 38:41-48

Clarke KR, Green RH (1988) Statistical design and analysis for a "biological effects" study. Mar Ecol Prog Ser 46:213-226

Clarke KR, Warwick RM (1994) Change in marine communities: an approach to statistical analysis and interpretation. Natural Environmental Research Council, Plymouth Marine Laboratory, Plymouth

Clarke KR, Warwick RM (2001) A further biodiversity index applicable to species lists: variation in taxonomic distinctness. Mar Ecol Prog Ser 216:265-278

Cognetti G, Maltagliati F (2000) Biodiversity and adaptive mechanisms in brackish water fauna. Mar Pollut Bull 40:7-14

Ferraro SP, Cole FA (1990) Taxonomic level and sample size sufficient for assessing pollution impacts on the southern California Bight macrobenthos. Mar Ecol Prog Ser 67:251-262

Ferraro SP, Cole FA (1992) Taxonomic level sufficient for assessing a moderate impact on macrobenthic communities in Puget Sound, Washington, USA. Can J Fish Aquat Sci 49:1184-1188 
Ferraro SP, Cole FA (1995) Taxonomic level sufficient for assessing pollution impacts on the southern California bight macrobenthos-revisited. Environ Toxicol Chem 1:1031-1040

Gravina MF, Ardizzone GD, Scaletta F, Chimenz C (1989) Descriptive analysis and classification of benthic communities in some Mediterranean coastal lagoons (central Italy). PSZN Mar Ecol 10:141-166

Guelorget O, Perthuisot J-P (1983) Le domain paralique. Expressions geologiques, biologiques et economiques du confinement. Travaux du Laboratoire de Geologie, Ecole Normale Superieure, Paris

Guelorget O, Perthuisot J-P (1992) Paralic ecosystems. Biological organization and functioning. Vie Milieu 42:215-251

Kjerfve B (1994) Coastal lagoons. In: Kjerfve B (ed) Coastal lagoon processes. Elsevier, Amsterdam, pp 1-8

Koutsoubas D, Dounas C, Arvanitidis C, Kornilios S, Petihakis G, Triantafyllou G, Eleftheriou A (2000) Macrobenthic community structure and disturbance assessment in Gialova lagoon, Ionian Sea. ICES J Mar Sci 57:1472-1480

Lardicci C, Rossi F, Castelli A (1997) Analysis of macrozoobenthic community structure after severe dystrophic crises in a Mediterranean coastal lagoon. Mar Pollut Bull 34:536-547

Legendre P, Legendre L (1998) Numerical ecology. Developments in environmental modelling, vol 20. Elsevier, Amsterdam

McArthur V, Koutsoubas D, Lambadariou N, Dounas C (2000) The meiofaunal community structure of a Mediterranean lagoon (Gialova lagoon, Ionian Sea). Helgol Mar Res 54:7-17

Nikolaidou A, Bourgoutzani F, Zenetos A, Guelorget O, Perthuisot J-P (1988) Distribution of molluscs and polychaetes in coastal lagoons in Greece. Estuar Coast Shelf Sci 26:337-350
Olsgard F, Somerfield PJ, Carr MR (1997) Relationships between taxonomic resolution and data transformations in analyses of a macrobenthic community along an established pollution gradient. Mar Ecol Prog Ser 149:173-181

Reizopoulou S, Thessalou-Legaki M, Nikolaidou A (1996) Assessment of disturbance in Mediterranean lagoons: an evaluation of methods. Mar Biol 12:189-197

Somerfield PJ, Clarke KR (1995) Taxonomic levels, in marine community studies, revisited. Mar Ecol Prog Ser 127:113-119

Warwick RM (1988) The level of taxonomic discrimination required to detect pollution effects on marine benthic communities. Mar Pollut Bull 19:259-268

Warwick RM, Clarke KR (1995) New“biodiversity" measures reveal a decrease in taxonomic distinctness with increasing stress. Mar Ecol Prog Ser 129:301-305

Warwick RM, Clarke KR (1998) Taxonomic distinctness and environmental assessment. J Appl Ecol 35:532-543

Warwick RM, Clarke KR (2001) Practical measures of marine biodiversity based on relatedness of species. Oceanogr Mar Biol Annu Rev 39:207-231

Warwick RM, Light J (2001) Death assemblages of molluscs on St. Martin's flats, Isles of Scilly: a surrogate for regional biodiversity? Biodivers Conserv 11:99-112

Warwick RM, Platt HM, Clarke KR, Agard J, Gobin J (1990) Analysis of macrobenthic and meiobenthic community structure in relation to pollution and disturbance in Hamilton harbour, Bermuda. J Exp Mar Biol Ecol 138:119-142 